\title{
PENERAPAN METODE VALUE FOR MONEY SEBAGAI TOLOK UKUR PENILAIAN KINERJA KEUANGAN PADA ORGANISASI SEKTOR PUBLIK DI DINAS KESEHATAN KOTA MANADO
}

\author{
Gabriela Thalia Wuwungan ${ }^{1}$, Jantje Tinangon ${ }^{2}$, Sintje Rondonuwu ${ }^{3}$ \\ 123Jurusan Akuntansi, Fakultas Ekonomi dan Bisnis, Universitas Sam Ratulangi, Jl. Kampus Bahu, Manado \\ 95115, Indonesia \\ E-mail : gabrielawuwungan@gmail.com
}

\begin{abstract}
In this era of globalization, many people consider the financial sector of public sector organizations as a waste and a source of funding. Loss of public trust in lost public sector organizations. In addition, accountability reports on public sector organizations are only oriented to "output" rather than "outcome". This discusses the phenomenon that public sector organizations pay more attention to the value of money that can be considered inputs, outputs, before the results that underlie the three main elements namely economy, efficiency and effectiveness. Research in the city of Manado using the value for money method, in terms of economy, efficiency and effectiveness. The analytical method used in this thesis research using descriptive qualitative methods, namely the results of interviews and with the data collected were analyzed and conclusions were collected. The results of the research obtained from the research results of the Manado City Health Office obtained the value for money method for economic measurement and efficiency, achieving good results. However, to measure success is still not good, decided one of the programs carried out has not been approved. Manado City Health Office should pay more attention to the results of the community in each program that is carried out, so that it is easier to find out which programs meet the requirements or not.
\end{abstract}

Keywords: value for money; economy; efficiency; effectiveness

\section{PENDAHULUAN}

Dalam era globalisasi ini, kinerja suatu organisasi sektor publik banyak menjadi sorotan. Masyarakat semakin cerdas dalam menilai suatu kinerja organisasi sektor publik, mereka mulai mempertanyakan akan nilai yang mereka peroleh atas pelayanan atau kinerja yang dilakukan oleh organisasi sektor publik. Masyarakat mempertanyakan apakah dana yang digunakan sesuai atau tidak dengan apa yang mereka terima dari program-program yang dilaksanakan. Kepercayaan masyarakat mulai hilang terhadap organisasi sektor publik diakibatkan kurangnya transparansi terhadap setiap pertanggungjawaban informasi keuangan yang dilakukan dalam organisasi. Banyak masyarakat yang berpikir bahwa organisasi sektor publik adalah sarang pemborosan, dan sumber kebocoran dana. Hal ini mengakibatkan munculnya fenomena agar organisasi sektor publik lebih memperhatikan value for money yang mempertimbangkan input, output dan outcome secara bersamaan dalam organisasi sektor publik.

Dinas Kesehatan Kota Manado merupakan salah satu dari organisasi sektor publik yang bergerak dalam bidang kesehatan dalam menyelenggarakan pelayanan kesehatan di kota Manado. Dinas Kesehatan Kota Manado melaporkan setiap pertangunggjawaban program yang telah dilakukan ke dalam LAKIP (Laporan Akuntabilitias Kinerja Instansi Pemerintah) sesuai dengan Permen PAN No. 29 tahun 2010. Faktanya ada beberapa permasalahan dalam pengukuran kinerja LAKIP salah satunya pelaksanaan program yang masih berorientasi pada 
"output" daripada "outcome". Adapun Dinas Kesehatan Kota Manado dimana Laporan Akuntabilitas kinerjanya masih berorientasi keluaran (ouput) dari pada hasil (outcome) dilihat dari indikator program yang dicapai belum melaporkan hasil (outcome). Sehingga Dinas Kesehatan Kota Manado hanya berfokus pada "penyerapan anggaran telah terlaksana serratus persen" atau "yang penting program sudah terlaksana" dan menggabaikan hasil yang mampu memberi pertanggungjawaban apakah pelaksanaan tugas pokok dan fungsi tersebut telah memenuhi kebutuhan masyarakat atau tidak. Diharapkan dengan menggunakan metode value for money mampu mempertimbangkan input, output dan terlebih outcome terhadap tujuan dari ketiga program tersebut. Tidak hanya melaporkan kalau program tersebut telah dilaksanakan, namun bisa dilihat dari dampak apakah sudah sesuai dengan tujuan dari program tersebut.

\section{TINJAUAN PUSTAKA}

Akuntansi. Kartikahadi et al. (2016) Akuntansi adalah suatu sistem infomrasi keuangan yang bertujuan untuk menghasilkan dan melaporkan informasi yang relevan bagi berbagai pihak yang berkepentingan. Menurut Sujarweni (2015) Akuntansi adalah suatu aktivitas jasa yang terdiri dari mencatat, mengklasifikasikan, dan melaporkan kejadian atau transaksi ekonomi yang akhirnya akan menghasilkan suatu informasi keuangan yang dibutuhkan oleh pihak-pihak tertentu untuk pengambilan keputusan.

Akuntansi Sektor Publik. Malahika (2018) Akuntansi sektor publik adalah suatu aktivitas dalam bidang publik yang menyediakan suatu bentuk laporan yang terjadi karena adanya transaksi ekonomi atau kegiatan mencatat yang menimbulkan adanya suatu laporan untuk mempertanggungjawabkan keuangan di bidang publik.

Akuntansi Pemerintahan. Menurut Sudaryo (2018) akuntansi pemerintahan tidaklah sama dengan akuntansi sektor publik dikarenakan cakupan akuntansi pemerintahan lebih luas daripada akuntansi sektor publik. Sujarweni (2015) Akuntasi pemerintahan adalah akuntansi yang bersangkutan dengan bidang keuangan negara, dari anggaran sampai dengan pelaksanaan dan pelaporannya, termasuk segala pengaruh yang ditimbulkannya.

Pengukuran Kinerja. Zubair et al. (2016) Pengukuran kinerja merupakan suatu proses penilaian kemajuan pekerjaan terhadap pencapaian tujuan dan sasaran yang telah ditentukan, termasuk informasi atas efisiensi penggunaan sumber daya dalam menghasilkan barang dan jasa, kualitas barang dan jasa, perbandingan hasil kegiatan dengan target, dan efektivitas tindakan dalam mencapai tujuan.

Indikator Pengukuran Kinerja. Menurut Indra Bastian yang dikutip dalam skripsi Rahajeng (2018) menyatakan bahwa indikator kinerja adalah ukuran kuantitatif dan kualitatif yang menggambarkan tingkat pencapaian suatu sasaran atau tujuan yang telah ditetapkan, dengan memperhitungkan indikator masukan (inputs), keluaran (output), hasil (Outcome), manfaat (benefits) dan dampak (impacts).

Informasi yang Digunakan untuk Pengukuran Kinerja. Menurut Mulyani et al. (2018) ada terdapat dua informasi yang digunakan dalam pengukuran kinerja yaitu yang pertama Informasi Finansial finansial diukur berdasarkan pada anggaran yang telah dibuat dan dilakukan dengan menganalisis varians (selisih suatu perbedaan) antara kinerja aktuan dengan yang dianggarkan. Dan yang kedua informasi nonfinansial Jenis informasi nonfinansial dapat dinyatakan dalam bentuk variable kunci (key variable) atau sering dianamakan sebagai key success factor, key result factor, atau pulse point.

Value for Money. Arisaudi (2016) Value for money merupakan tolok ukur dari pengukuran kinerja pada organisasi pemerintah yang berdasarkan pada ukuran ekonomis, efisiensi, dan efektivitas. Sedangkan menurut Halim et al. (2014) Value for money merupakan konsep untuk mengukur ekonomi, efesiensi dan efektivitas kinerja program, kegiatan dan organisasi, yaitu ekonomi terkait sejauh mana organisasi sektor publik 
meminimalisir input resource yang digunakan yaitu dengan menghindari pengeluaran yang boros dan tidak produktif, efisiensi terkait pencapaian output yang maksimum dengan input tertentu atau penggunaan input yang terendah untuk mencapai output tertentu dan efektivitas tingkat pencapaian hasil program dengan target yang ditetapkan.

Pengukuran Ekonomi. Menurut Mahmudi dikutip dalam jurnal Syadiyah (2016) pengukuran ekonomis dapat dinyatakan dalam rumus berikut :

$$
\text { Ekonomis }=\frac{\text { Input }}{\text { harga Input }} \times 100 \%
$$

Kriteria penilaian tingkat ekonomis adalah:

a) Jika diperoleh nilai perbandingan kurang dari $100 \%$ maka berarti ekonomis.

b) Jika diperoleh nilai sama dengan $100 \%$ maka berarti ekonomis berimbang.

c) Jika diperoleh nilai lebih dari $100 \%$ maka berarti tidak ekonomis.

Pengukuran Efisiensi. Menurut Mardiasmo (2018) Pengukuran efisiensi dapat dinyatakan dalam rumus berikut :

$$
\text { Efisiensi }=\frac{\text { ouput }}{\text { Input }} \times 100 \%
$$

Kriteria penilaian tingkat Efisiensi adalah:

a) Jika diperoleh nilai perbandingan lebih dari $100 \%$ maka, Efisien.

b) Jika diperoleh nilai sama dengan $100 \%$ maka, berarti efisien berimbang.

c) Jika diperoleh nilai kurang dari $100 \%$ maka, tidak efisien.

Pengukuran Efektivitas. Mardiasmo (2018) Efektivitas adalah ukuran berhasil tidaknya suatu organisasi mencapai tujuannya. Suatu organisasi atau program dinilai efektif apabila output yang dihasilkan memenuhi tujuan yang diharapkan.

Penelitian Terdahulu. Susanto (2019) menemukan bahwa kinerja keuangan pemerintah daerah kota Mataram rasio efektifitas dikategorikan sudah efektif, rasio efisiensi dikategorikan tidak efisien, rasio kemandirian pengelolaan keuangan daerah masih rendah, rasio aktifitas masih kurang baik, rasio pertumbuhan pada komponen PAD kurang baik, sementara komponen rasio pendapatan daerah dikategorikan sedang, untuk pertumbuhan belanja dikategorikan kurang baik. Sartono (2018) menyatakan bahwa kinerja keuangan pemerintah daerah kota magelang tahun 2012 - 2016 rasio ekonomis cukup ekonomis. Untuk rasio efisiensi kurang efisien dan untuk rasio efektivitas tergolong sangat efektif. Pramono (2014) menyatakan bahwa kinerja keuangan Pemkot Surakarta yang masih kurang baik adalah aspek kemandirian dan aspek keserasian. Sedangkan untuk tingkat efesiensi dan efektifitas sudah sangat efisien dan efektif. Pratiwi et al. (2018) menemukan bahwa pengukuran kinerja perusahaan dengan menggunakan metode Balanced Scorecard pada perusahaan Air Minum Surakarta menunjukan dalam perspektif keuangan dan perspektif bisnis internal hasilnya baik. sedangkan perspektif pelanggan dan perspektif pembelajaran dan pertumbuhan memiliki hasil yang kurang baik.

\section{METODE PENELITIAN}

Jenis Data. Jenis data yang digunakan oleh penelitian ini adalah data kuantitatif yaitu berupa laporan pertanggungjawaban dari program obat dan perbekalan kesehatan, program pengadaanm peningkatan dan perbaikan sarana dan prasarana puskesmas, serta program pengawasan obat dan makanan tahun 2018. Dan data kualitatif yaitu berupa gambaran umum dan struktur organisasi dari Dinas Kesehatan kota Manado serta hasil wawancara pengukuran efektifitas dari ketiga program tersebut.

Sumber Data. Sumber data dalam penelitian ini adalah data primer, yaitu data yang diperoleh langsung di Dinas Kesehatan kota Manado dan UPT Puskesmas Bahu dengan meminta data-data yang diperlukan serta melakukan wawancara secara langsung mengenai pengukuran efektifitas. 
Proses Analisis Data. Tahap pertama mengumpulkan data berdasarkan wawancara mengenai informasi yang diperlukan dalam metode value for money yaitu berupa laporan pertanggung jawaban dari program obat dan perbekalan kesehatan, program pengadaanm peningkatan dan perbaikan sarana serta program pengawasan obat dan makanan. Tahap kedua melakukan pengukuran dengan menerapkan metode value for money 3E (ekonomis, efisiensi dan efektivitas) untuk menilai kinerja dari organisasi sektor publik di Dinas Kesehatan Kota Manado. Tahan ketiga setelah melakukan pengukuran, hasil dari pengukuran tersebut dicocokan dengan kriteria dari tiga elemen. Dan tahap kelima, menarik kesimpulan dari pembahasan yang telah didapatkan dari hasil pengukuran yang dilakukan sebelumnya.

\section{HASIL DAN PEMBAHASAN}

\subsection{Hasil Penelitian}

Dalam mewujudkan pelaksanaan pembangunan kesehatan, pada tahun 2018 Dinas Kesehatan Kota Manado melakukan 14 program. Dari keempat belas program tersebut, peneliti hanya mengukur tiga program yaitu program obat dan perbekalan kesehatan, program pengadaan, peningkatan dan perbaikan sarana dan prasarana Puskesmas dan program pengawasan obat dan makanan. Berikut ini indikator kinerja dari ketiga program tersebut :

1. Program Obat dan Perbekalan Kesehatan

Input : Dana

Ouput : Terlaksananya pengadaan obat dan perbekalan kesehatan di puskesmas

Outcomes : Terpenuhinya obat-obatan di Puskesmas

2. Program Pengadaan, Peningkatan dan Perbaikan Saran dan Prasarana Puskesmas

Input : Dana

Output : Presentasi pencapaian kegiatan pengadaan sarana dan prasarana di Puskesmas

Outcomes : Dapat menunjang kegiatan operasional kesehatan di puskesmas

3. Program Pengawasan Obat dan Makanan

Input : Dana

Output : Presentase pelaksanaan kegiatan pengawasan dan keamanan kesehatan makanan hasil industri

Outcomes : tercapainya keamanan dan kesehatan pangan yang beredar di masyarakat

\subsection{Pembahasan}

Pengukuran Ekonomi. Pengukuran ekonomi dikatakan ekonomis apabila organisasi sektor publik mampu mengurangi biaya-biaya yang tidak perlu, semakin kecil nilai dari rasio ekonomi, maka semakin baik kinerja Dinas Kesehatan Kota Manado dalam ketiga program tersebut.

Tabel 1. Hasil Pengukuran Ekonomis

\begin{tabular}{lccc}
\hline \multicolumn{1}{c}{ Program } & Realisasi & Target & \multicolumn{1}{c}{$\begin{array}{c}\text { Tingkat } \\
\text { Ekonomis }\end{array}$} \\
\hline $\begin{array}{l}\text { Program Obat dan Perbelakan } \\
\begin{array}{l}\text { Kesehatan } \\
\text { Program Pengadaan, }\end{array}\end{array}$ & 3.242 .697 .142 & 3.856 .452 .000 & $84,08 \%$ \\
$\begin{array}{l}\text { Peningkatan dan Perbaikan } \\
\text { Sarana dan Prasarana }\end{array}$ & 45.535 .108 .744 & 52.672 .813 .000 & $86,44 \%$ \\
$\begin{array}{l}\text { Puskesmas } \\
\text { Program Pengawasan Obat } \\
\text { dan Makanan }\end{array}$ & 98.079 .500 & 101.175 .900 & \\
\hline
\end{tabular}

Sumber : Data diolah, 2019 
Pengukuran Efisiensi. Pengukuran Efisiensi dikatakan efisien apabila pencapaian nilai output lebih besar dibandingkan dengan nilai input. Kinerja Dinkes Kota Manado terhadap program obat dan perbekalan kesehatan, program pengadaan, peningkatan dan perbaikan saran dan prasarana, dan program pengawasan dan pengendalian makanan dikatakan efisien jika nilai yang dihasilkan adalah lebih dari 100\%. Semakin besar nilai efisiensi maka semakin baik kinerja keuangan Dinkes Kota Manado.

Tabel 2. Hasil Pengukuran Efisien

\begin{tabular}{|c|c|c|c|}
\hline Kegiatan & Ouput & Input & Tingkat Efisien \\
\hline $\begin{array}{l}\text { Program Obat dan Perbelakan } \\
\text { Kesehatan }\end{array}$ & $96 \%$ & $84,08 \%$ & $114,17 \%$ \\
\hline $\begin{array}{l}\text { Program Pengadaan, Peningkatan dan } \\
\text { Perbaikan Sarana dan Prasarana } \\
\text { Puskesmas }\end{array}$ & $95 \%$ & $86,44 \%$ & $109,90 \%$ \\
\hline $\begin{array}{l}\text { Program Pengawasan Obat dan } \\
\text { Makanan }\end{array}$ & $98 \%$ & $96,93 \%$ & $101,10 \%$ \\
\hline
\end{tabular}

Sumber : Data diolah, 2019

Pengukuran Efektivitas. Pengukuran efektivitas ini pencapaian hasil program dengan tujuan yang ditetapkan dengan membandingkan antara outcome dan output. Pada umumnya, pengukuran ini sangat sulit karena outcome tidak bisa dikuantifikasikan. Suatu program dinilai efektif apabila output yang dihasilkan memenuhi tujuan yang diharapkan.

Untuk pengukuran efektivitas, peneliti menggunakan wawancara dengan beberapa pegawai di Puskesmas Bahu dan masyarakat yang tinggal di dekat pasar bahu, mengenai mengenai ketiga program dari Dinas Kesehatan Kota Manado. Peneliti mengambil objek Puskesmas Bahu karena Puskesmas Bahu merupakan salah satu UPT dari Dinas Kesehatan Kota Manado yang menjadi objek dari program obat dan perbekalan kesehatan dan program pengadaan, peningkatan, dan perbaikan sarana dan prasarana puskesmas. Untuk program pengawasan obat dan makanan, tahun 2018 Dinas Kesehatan kota Manado sendiri melakukan kegiatan pengawasan keshatan makanan hasil industri di Pasar Bahu. Pengawasan dari hasil industri tersebut berupa mie, tahu, tempe dan hasil industri lainnya di pasar Bahu.

Hasil Pengukuran Value For Money Pada Program Obat dan Perbekalan Kesehatan. Dari hasil pengukuran value for money Pada program obat dan perbekalan kesehatan dengan kegiatan pengadaan obat dan perbekalan kesehatan di puskesmas oleh Dinas Kesehatan Kota Manado, hasil menunjukan pengukuran ekonomi dan efisien sangat baik yaitu mencapai kriteria ekonomis dan efsien. Dikatakan ekonomis, disebabkan Dinas Kesehatan Kota Manado mampu meminimalisir dana yang digunakan untuk program ini. Dan dikatakan efisien, disebabkan ouput dari program ini hampir memenuhi target yaitu sebesar 96\% dengan input-nya yang tidak terlalu besar. Dalam kegiatan ini, anggaran yang dianggarkan sebesar Rp 3.856.452.000 dan realisasinya sebesar Rp 3.242.697.142. Hal ini menunjukan bahwa dalam pelaksanaaan program ini, Dinas kesehatan kota Manado mampu meminimalisir dana yang digunakan yaitu dengan menghemat biaya sebesar Rp 613.754.858. Meskipun penghematan biaya tersebut terbilang cukup besar, akan tetapi program ini berjalan dengan baik sehingga ouput dari program ini hampir memenuhi target yaitu $96 \%$.

Pengukuran efektivitas dalam program obat dan perbekalan kesehatan dengan kegiatan pengadaan obat dan perbekalan kesehatan dilakukan dengan wawancara di salah satu UPT Dinas kesehatan kota Manado yaitu Puskesmas Bahu. Program ini dengan kegiatan pengadaan obat dan perbekalan kesehatan masih belum mencapai tujuan dari program ini. Karena menurut 3 dari 5 responden yang mengatakan kalau obat yang mereka perlukan tidak tersedia, atau bisa dibilang program obat dan perbekalan kesehatan di Puskesmas Bahu tidak 
terpenuhi atau tidak efektif karena tidak memenuhi tujuannya yaitu terpenuhinya obat-obat di puskesmas khususnya Puskemas Bahu.

Hasil Pengukuran Value For Money Pada Program Pengadaan, Peningkatan dan Perbaikan Sarana dan Prasarana Puskesmas. Dari hasil pengukuran value for money pada program pengadaan, peningkatan dan perbaikan sarana dan prasarana puskesmas dengan Kegiatan pengadaan sarana dan prasarana di puskesmas oleh Dinas Kesehatan Kota Manado, hasil menunjukan pengukuran ekonomi dan efisien sangat baik yaitu mencapai kriteria ekonomis dan efsien. Dikatakan ekonomis, disebabkan Dinas Kesehatan Kota Manado menganggarkan program ini sebesar Rp 52.672.813.000 dan realisasinya sebesar Rp 45.535.108.744 dengan hasil pengukuran ekonominya mencapai 86,44\%. Dinas Kesehatan Kota Manado meminimalisir dana yang digunakan untuk program ini dengan penghematan sebesar Rp 7.137.704.256. Program ini juga dikatakan efisien disebabkan oleh ouputnya mencapai 95\% atau hampir memenuhi target yang ditetapkan dengan inputnya sebesar $86,44 \%$ tidak melebihi dari outputnya dengan pengukuran efisiennya mencapai $109,90 \%$. Meskipun penghematan yang dilakukan cukup besar, akan tetapi program ini berjalan dengan baik sehingga outputnya hampir memenuhi target $100 \%$.

Pada tahun 2018 puskesmas bahu mendapatkan sarana yang baru yaitu ambulans. Hasil wawancara dengan lima responden di Puskesmas Bahu mengatakan bahwa pengadaan ambulans sangat membantu pelayanan kesehatan. Mereka menyatakan bahwa ambulance tersebut digunakan sebagai mana mestinya dengan membantu banyak kegiatan operasional kesehatan di Puskesmas Bahu. Dari hasil ini, dapat dikatakan bahwa kegiatan pengadaan sarana dan prasarana di Puskesmas Bahu sudah efektif atau program ini sudah memenuhi tujuannya.

Hasil Pengukuran Value For Money Pada Program Pengawasan Obat dan Makanan. Dari hasil pengukuran value for money pada program pengawasan obat dan makanan dengan kegiatan pengawasan dan keamanan kesehatan makanan hasil industri oleh Dinas Kesehatan Kota Manado, hasil menunjukan pengukuran ekonomi dan efisien cukup baik yaitu mencapai kriteria cukup ekonomis dan efsien. Dikatakan cukup ekonomis, disebabkan Dinas Kesehatan Kota Manado menganggarkan program ini sebesar Rp 101.175.900 dan realisasinya sebesar Rp 98.079.500 dengan hasil pengukuran ekonomi sebesar 96,93\%. Dikatakan cukup ekonomis karena program ini penyerapan anggarannya hampir terserap dengan baik. namun Dinas Kesehatan Kota Manado mampu meminimalisir dana dalam program ini dengan menghemat biaya sebesar Rp 3.096.400. Program ini juga dikatakan cukup efisien disebabkan oleh ouputnya mencapai $98 \%$ atau hampir memenuhi target yang ditetapkan dengan inputnya sebesar 96,93\% tidak melebihi dari outputnya dengan pengukuran efisiennya mencapai $101,10 \%$ atau hampir tidak efesien. Meskipun penghematan dalam program ini tidak terlalu besar, namun program ini berjalan dengan baik sehingga outputnya hampir memenuhi target $100 \%$.

Pada tahun 2018 Dinas Kesehatan Kota Manado melakukan pengawasan keamanan kesehatan makanan hasil industri di Pasar Bahu. Ada salah satu responden merupakan penjual midal yang dari tahun ke tahun membeli bahan makanannya di pasar bahu dan hasilnya tidak terjadi apa-apa semuanya masih sehat. Dari hasil wawancara ini menunjukan bahwa tujuan tercapainya keamanan dan kesehatan pangan yang beredar di masyrakat sudah memenuhi tujuannya atau bisa dikatakan program ini efektif.

Selain pengawasan kemanan kesehatan makanan, Dinas Kesehatan Kota Manado juga melakukan pengawasan terhadap obat yang di edarkan di puskesmas-puskesmas. Berdasarkan wawancara dengan kepala bagian farmasi dan salah satu pekerja di apotek Puskesmas Bahu, kegiatan pengawasan ini berjalan dengan baik serta sangat bermanfaat. Menurut mereka bahwa program ini sangat membantu dalam proses manajemen obat dan menyadarkan mereka untuk lebih teliti dalam proses manajemen obat. 


\section{KESIMPULAN DAN SARAN}

\subsection{Kesimpulan}

Berdasarkan hasil dari penerapan metode value for money terhadap penilaian kinerja terhadap ketiga program di Dinas Kesehatan Kota Manado maka dapat disimpulkan beberapa hal berikut ini :

1 Penilaian kinerja Dinas Kesehatan Kota Manado di tahun 2018 dinilai dari sisi ekonomi terhadap program obat dan perbekalan kesehatan, program pengadaan, peningkatan dan perbaikan sarana dan prasarana puskesmas dan program pengawasan obat dan makanan dinyatakan sudah ekonomis.

2 Penilaian kinerja Dinas Kesehatan Kota Manado di tahun 2018 dinilai dari sisi efisiensi terhadap program obat dan perbekalan kesehatan, program pengadaan, peningkatan dan perbaikan sarana dan prasarana puskesmas dan program pengawasan obat dan makanan dinyatakan sudah efisien.

3 Penilaian kinerja Dinas Kesehatan Kota Manado di tahun 2018 dinilai dari sisi efektifitas satu dari ketiga program tersebut dinyatakan tidak efektif. Artinya Dinas Kesehata Kota Manado harus lebih memperhatikan outcomes dari suatu program yang akan dilaksanakan. Meskipun program tersebut sudah terlaksana dengan baik, namun belum tentu program itu efektif. Sehingga setiap program dari Dinas Kesehtan Kota Manado tidak sekedar terlihat "yang penting sudah terlaksanakan" namun lebih memperhatikan hasil program tersebut apakah bermanfaat untuk masyarakat atau tidak.

\subsection{Saran}

Berdasarkan penelitian yang telah dilakukan dan kesimpulan diatas, peneliti memberikan beberapa saran dari penulis yang diharapkan dapat memberikan manfaat. Saran tersebut sebagai berikut :

1 Kinerja Dinas Kesehatan Kota Manado terhadap program obat dan perbekalan kesehatan, program pengadaan, peningkatan dan perbaikan sarana dan prasarana puskesmas dan program pengawasan obat dan makanan diharapkan untuk dapat mempertahankan di tahun-tahun berikutnya untuk tetap ekonomis.

2 Kinerja Dinas Kesehatan Kota Manado dalam hal efesien terhadap program obat dan perbekalan kesehatan, program pengadaan, peningkatan dan perbaikan sarana dan prasarana puskesmas dan program pengawasan obat dan makanan harus tetap dipertahankan dan ditingkatkan.

3 Kinerja Dinas Kesehatan Kota Manado dalam hal efektivitas perlu ditingkatkan. Dalam pengukuran ini diharapkan Dinas Kesehatan Kota Manado lebih memperhatikan outcomes dari masyarakat tentang program-program yang dilaksanakan. Agar bisa diketahui apa yang masih kurang dan apa yang masih dibutuhkan dalam pelayanan kesehatan di puskesmas-puskesmas yang ada. Yang paling penting melalui masyarakat, bisa diketahui tujuan dari program-program tersebut sudah tercapai atau belum tercapai.

\section{DAFTAR PUSTAKA}

Arisaudi, Z. (2016). Analisis Pengukuran Kinerja Pelaksanaan Anggaran Belanja Dengan Value For Money Pada Dinas Pekerjaan Umum Bina Marga Dan Pengelolaan Sumber Daya Air Kota Palembang. Skripsi. Universitas Muhamadiyah, Palembang, Indonesia. http://repository.um-palembang.ac.id/id/eprint/1334/

Halim, A., \& Kusufi, M. Syam. (2014). Teori, Konsep, dan Aplikasi Akuntansi Sektor Publik. Edisi ke-2. Jakarta: Salemba Empat.

Kartikahadi, H., Syamsul, R., \& Siregar, S. (2016). Akuntansi Keuangan Berdasarkan SAK Berbasis IFRS Buku 1. Jakarta: Salemba Empat. 
Malahika, J., Karamoy, H., \& Pusung, R. (2018). Penerapan Sistem Keuangan Desa (SISKEUDES) pada organisasi pemerintahan desa (Studi kasus di Desa Suwaan Kecamatan Kalawat Kabupaten Minahasa Utara). Going Concern : Jurnal Riset Akuntansi, 13(04), 578 - 583. https://doi.org/10.32400/gc.13.04.21514.2018

Mardiasmo, (2018). Akuntansi Sektor publik. Yogyakarta: Penerbit Andi.

Mulyani, S., Suzan, L., Dagara, Y., \& Alam, M. (2018). Sistem Informasi Akuntansi: Aplikasi Di Sektor Publik. Bandung: Unpad Press.

Pramono, J. (2014). Analisis Rasio Keuangan untuk Menilai Kinerja Keuangan Pemerintah Daerah (Studi Kasus Pada Pemerintah Kota Surakarta). Jurnal Ilmiah Manajemen dan $\begin{array}{llllll}\text { Akuntansi STIE } & \text { AMA. } & 7(13) & 83 & - & 112 .\end{array}$ http://jurnal.stieama.ac.id/index.php/ama/article/view/97

Pratiwi, V., Wibowo, E., Utami, S. S. (2018). Analisis Pengukuran Kinerja Perusahaan Dengan Menggunakan Metode Balanced Scorecard Pada Perusahaan Daerah Air Minum Surakarta Tahun 2015 - 2016. Junral Ekonomi dan Kewirausahaan. 18(9) 208 - 218. http://ejurnal.unisri.ac.id/index.php/Ekonomi/article/view/2379

Rahajeng, A. D. (2018). Analisis Pengukuran Kinerja Organisasi Sektor Publik Dengan Pendekatan Value For Money (Studi Kasus Di Dinas Pendidikan Kabupaten Sleman). Skripsi. Universitas Sanata Dharma, Yogyakarta, Indonesia. https://repository.usd.ac.id/27247/2/142114023_full.pdf

Sartono, A. (2018). Analisis Pengukuran Kinerja Keuangan Pemerintah Daerah Kota Magelang Tahun 2012 - 2016 Berdasarkan Konsep Value For Money. Skripsi. Sekolah Tinggi Ilmu Ekonomi Widya Wiwaha, Yogyakarta, Indonesia. http://eprint.stieww.ac.id/133/

Sudaryo, Y. (2018). Keuangan Di Era Otonomi Daerah.Yogyakarta: Penerbit Andi.

Sujarweni, W. (2015). Akuntansi Sektor Publik. Yogyakarta: Pustaka Bru Press

Susanto, H. (2019). Analisis Rasio Keuangan Untuk Mengukur Kinerja Keuangan Pemerintah Daerah Kota Mataram. Jurnal Ilmu Manajemen Dan Bisnis. 7(1), 81 - 92. https://doi.org/10.29303/distribusi.v7i1.67

Syadiyah, K. (2016). Analisis Value For Money Dalam Pengukuran Kinerja Keuangan Pada Badan Penanggulangan Bencana Daerah Kabupaten Sidoarjo. Jurnal Ekonomi $\begin{array}{lllll}\text { Akuntansi } & \text { Equity. } & 2(4), & 9 & -\end{array}$ http://fe.ubhara.ac.id/ojs/index.php/equity/article/view/192.

Zubair, E. \& Koton, Y,P. (2016). Pengelolaan Danau Limboto Dalam Perspektif Kebijakan Publik. Yogyakarta: Penerbit CV Budi Utama. 